\title{
O valor econômico da cultura: um debate sobre formas de apropriação do conceito de cultura
}

\section{Luciana Requião}

Resumo: Este artigo apresenta questões preliminares que fundamentam o projeto de pesquisa "A Cultura como Mercadoria: manifestações culturais a serviço da valorização do capital". São discutidas as formas como a noção de cultura se apresenta hoje nos discursos políticos e na fala do empresariado que tem interesse em investir na chamada economia da cultura. A cultura é, em última análise, descrita como um "fator de desenvolvimento econômico". De outro modo, defendemos a idéia de uma política de ação cultural pela qual todos possam de forma ativa produzir cultura.

Palavras-chave: cultura; economia; capital

Abstract: This article present previous questions that base the research project "the Culture as Merchandise". The forms as the culture notion is present in the politician's and the bourgeoisie's speeches are discussed. The culture is, in last analysis, described as a "factor of economic development". In another way we defend the idea of one politics of cultural action that promotes a culture where all can be an active cultural producer.

Keywords: culture; economy; capital 


\section{Apresentação - o ponto de partida 1 - Cultura e Economia}

"O desenvolvimento divorciado de seu contexto humano e cultural não é mais do que um crescimento sem alma" (CUÉLLAR, 1997, p. 21). Essa é a frase que abre a síntese do relatório da Comissão Mundial de Cultura e Desenvolvimento da Unesco. O relatório foi fruto da reunião promovida pelas Nações Unidas, em 1992, onde economistas, cientistas sociais e artistas, entre outros, formaram uma comissão para "explorar as interações entre cultura e desenvolvimento econômico" (idem).

No Brasil, os estudos sobre a economia da cultura são relativamente recentes, assim como o levantamento de dados que atestem a importância econômica que esse setor vem representando no país. Porém, os estudos já existentes indicam que "a economia da cultura é, dos mercados emergentes, um dos apontados como dos mais importantes e promissores do início do século XXI" (HOLLANDA, 2002, p. 31). Segundo pesquisa encomendada pelo Ministério da Cultura e realizada pela Fundação João Pinheiro em 1998, no Brasil, no ano de 1997, foram gastos R \$ 6,5 bilhões no setor, representando 1\% do Produto Interno Bruto (PIB). Segundo a pesquisa, em 1997 havia 510 mil pessoas empregadas na produção cultural nacional.

Isso representa um contingente $90 \%$ maior que pessoas que trabalham nas atividades de fabricação de equipamentos e material elétrico e eletrônico; 53\% superior ao da indústria automobilística e de autopeças; e $78 \%$ superior ao de empregados em serviços industriais de utilidade pública (energia elétrica, distribuição de água e esgoto e equipamentos sanitários) ${ }^{1}$.

O ex-Ministro da Cultura Gilberto Gil vinha defendendo um maior investimento por parte do governo e da iniciativa privada nos setores culturais. O ministro parte de dados econômicos apresentados pela Unesco:

${ }^{1}$ Disponível em http://forbesbrasil.uol.com.br/Edicoes/122/artigo11702-2.asp, consultada em 28 de agosto de 2007.

154 O valor econômico da cultura:... 
Atualmente, de acordo com dados da Conferência das Nações Unidas para a Educação, Ciência e Cultura (Unesco), 8\% da riqueza gerada em todo o mundo têm origem na economia criativa. Outro estudo das Nações Unidas revela que a movimentação financeira de produtos e serviços culturais atinge cerca de US\$ 1,3 trilhão em todo o mundo, com expectativa de crescimento médio à taxa de $10 \%$ ao ano ${ }^{2}$.

Outros dados ratificam a importância conferida à cultura como "fator de desenvolvimento econômico"3. Em pesquisa realizada pelo IBGE, publicada em 2006, foi identificado que em 2003 havia 290 mil empresas culturais no Brasil movimentando "uma receita líquida de $R$ \$ 156 bilhões de reais e custos de $\mathrm{R} \$ 114$ bilhões o que indica uma participação do setor cultural de 6,5\% dos custos totais e de 7,9\% na receita líquida total" 4 , e que a cultura seria o quarto item de consumo das famílias. Esse mesmo estudo identificou que, em relação ao total das pessoas ocupadas no Brasil, a população ocupada em "atividades vinculadas à cultura [...] apresentou um percentual de 4,5\%, em 2004, gerando uma estimativa que ultrapassa os 3,7 milhões de trabalhadores neste setor" (IBGE, 2006, p. 99) 5

Segundo o economista Fábio Sá Earp, a economia da cultura faria parte de um bloco maior chamado de economia do entretenimento, que englobaria também a economia do uso do tempo, a economia do esporte e a economia do turismo (EARP, 2002, p. 8). Estudos como o de Earp e de Luiz Gonzaga Godoi Trigo (2003), por exemplo, demonstram que, em geral, a noção de cultura está relacionada à idéia de lazer. Assim, a economia do entretenimento seria,

\footnotetext{
${ }^{2}$ Matéria encontrada em www.cultura.gov.br/noticias/na_midia, consultada em 27 de novembro de 2006.

${ }^{3} \mathrm{O}$ próprio texto disponibilizado no site do Ministério da Cultura sobre o histórico da criação do MINC atribui a separação, em 1985, da Cultura e da Educação ao fato da Cultura ser "cada vez mais um setor de grande destaque na economia do País, como fonte de geração crescente de empregos e renda" (www.cultura.gov.br consultado em 3 de março de 2009).

${ }^{4}$ Encontrado em www.cultura.gov.br/noticias/noticias_do_minc, consultada em 16 de agosto de 2007.

${ }^{5}$ Vale notar que estes dados são referentes às pessoas ocupadas formalmente, sem contar os trabalhos de caráter informal, muito comum no setor cultural.
} 
Uma intrincada rede que agrupa em um mesmo fenômeno atividades que, na origem, são diferentes (esportes, notícias, arte, educação, lazer, turismo, show-business), mas que se articulam enquanto mercadorias destinadas a um consumo específico caracterizado pelo prazer. Surge um grande e difuso espaço que pode ser denominado "entretenimento" - ou espetáculo (TRIGO, 2003, p. 21-22).

Mas quais seriam, então, as atividades produtivas do setor cultural? Baseado na elasticidade e subjetividade do conceito de cultura o ex-ministro da cultura Gilberto Gil indica a tendência atual:

A ampliação do conceito de cultura também passa a reconhecer e incorporar setores da Educação e de dimensões das Telecomunicações - que passam a reconhecer como culturais atividades econômicas, tipos de emprego e ramos desses segmentos ${ }^{6}$.

O IBGE (2006) ao organizar o seu "Sistema de Informações e Indicadores Culturais" referente ao ano de 2003 partiu de uma concepção de cultura que a relaciona as atividades econômicas geradoras de bens e serviços.

O setor cultural foi definido de uma maneira empírica, tomando-se como referência inicial a definição da Unesco sobre as atividades culturais relacionadas [...] à criação, produção, e comercialização de conteúdos que são intangíveis e culturais em sua natureza (IBGE, 2006, p. 13).

As atividades do setor cultural foram dividas em grandes grupos formados pela indústria de transformação; pelo comércio; pelas atividades de transporte, armazenagem e comunicação; pelas atividades imobiliárias, aluguéis e serviços prestados às empresas; pelo setor de educação; e por um setor denominado como outros serviços coletivos, sociais e pessoais onde se inclui as atividades recreativas, culturais e desportivas (IBGE, 2006).

\footnotetext{
${ }^{6}$ Depoimento do ex-ministro Gilberto Gil encontrado em www.cultura.gov.br/noticias/ noticias_do_minc, consultada em 16 de agosto de 2007.
}

156 O valor econômico da cultura:... 
Os produtos culturais também foram detalhados e incluem artefatos de madeira e decoração; produtos impressos como jornais, revistas ou cadernos; produtos de áudio gravados como os CDs e DVDs e até mesmo o aluguel desses itens; eletrodomésticos para a reprodução de vídeo ou áudio; artigos da informática; brinquedos, jogos e material para o lazer; serviços de TV por assinatura e internet; atividades de cultura, lazer e festas; educação profissional e atividades de ensino; serviços e produtos da área da telefonia; e instrumentos e acessórios musicais.

Os profissionais dessa área foram classificados em 62 ocupações diferentes, entre elas músicos, dançarinos e atores; professores, arquivologistas e produtores; locutores, designers e cinegrafistas; técnicos em operação de rádio e televisão; decoradores, encadernadores e reparadores de instrumentos musicais.

Como se pode perceber através dos itens descritos acima, a noção de cultura é colocada de forma bem abrangente e relacionada a atividades comerciais. Tais atividades, por sua vez, se relacionam ao uso do tempo livre, do lazer, e ao consumo de produtos e serviços ditos culturais.

De acordo com os dados produzidos pelos relatórios indicados, a cultura em sua forma mercadoria ou como um serviço estaria expandindo um dos setores mais lucrativos deste século, o setor cultural. Por outro lado, a exemplo do que vem ocorrendo em outros setores da área social como a educação e a saúde, a cultura, hoje entendida como um "fator de desenvolvimento econômico" vem deixando de ser uma obrigação do Estado e um direito do cidadão passando a constar nas estratégias de marketing de empresas. Assim, nasce o conceito de "marketing cultural", amparado pela noção tão em voga nos dias de hoje: a "responsabilidade social". 


\section{2 - O marketing cultural}

Longe de se dispor a atender às questões sociais de forma desinteressada, a responsabilidade social, conforme a própria definição do Instituto Ethos, entidade criada em 1998 para promover a prática de responsabilidade social nas empresas, é entendida da seguinte forma:

A filantropia trata basicamente de ação social externa da empresa, tendo como beneficiário principal a comunidade em suas diversas formas $e$ organizações. A Responsabilidade Social foca a cadeia de negócios da empresa e engloba preocupações com um público maior (acionistas, funcionários, prestadores de serviço, fornecedores, consumidores, comunidade, governo e meio ambiente), cujas demandas e necessidades a empresa deve buscar entender e incorporar em seus negócios. Assim, a Responsabilidade Social trata diretamente dos negócios da empresa e de como ela os conduz'.

Através de um setor chamado de marketing cultural as empresas passam a incorporar em suas estratégias comerciais o patrocínio a projetos culturais. A economista Ana Carla Fonseca Reis ensina em seu livro "Marketing Cultural e Financiamento da Cultura":

A convicção, burilada com a divulgação permanente de exemplos exitosos e com a percepção de que nenhuma empresa pode esgotar seu potencial de negócios se estiver cercada por um mar de carências, é a de que uma parceria entre projetos sociais e culturais é indiscriminadamente generosa (REIS, 2003, p. 34).

Tendo em vista a afirmação acima, a economista continua dizendo que "o processo de seleção de projetos culturais é muito semelhante ao fluxo seguido pelas outras ferramentas de comunicação. [...] Ele deriva da estratégia de marketing da empresa" (idem, p. 67). A economista destaca os objetivos a serem alcançados com os investimentos em cultura que buscam ao final do processo, fundamentalmente, um retorno financeiro maior do que o que o projeto lhe custou. Em ordem decrescente, conforme a autora, os objetivos são (idem, p. 71):

${ }^{7}$ www.ethos.org.br, consultada em 5 de outubro de 2007.

\begin{tabular}{l|l}
\hline 158 & O valor econômico da cultura:...
\end{tabular} 
- Ganho de imagem;

- Agregação de valor à marca

- Reforço do papel social da empresa;

- A obtenção de benefícios fiscais;

- Retorno de mídia (publicidade gratuita);

- Aproximação do público-alvo.

Os benefícios fiscais mencionados são possíveis graças às políticas públicas implementadas no Brasil, que nos últimos governos vêm movimentando a chamada economia da cultura mediante políticas de fortalecimento do mercado cultural. O papel do Estado é o de criar as condições para ampliação desse mercado cultural, diretriz ampliada no Governo Lula, pelo ex-ministro Gilberto Gil:

O Estado tem um papel vital no fortalecimento da economia da cultura, seja no levantamento do potencial, seja no planejamento das ações, na articulação dos agentes econômicos e criativos, na mobilização da energia social disponível, no fomento direto, na regulação das relações entre agentes econômicos, na mediação dos interesses dos agentes econômicos e dos interesses da sociedade, assim como na fiscalização das atividades. É um papel múltiplo, que exige vontade política, qualificação institucional e recursos. Não se trata de reabilitar o Estado produtor de cultura, ou o Estado dirigista. Ao contrário. Parte-se do princípio de que o Estado pode e deve estimular um ambiente favorável ao desenvolvimento de empresas e criadores, para que o mercado possa ampliar-se e realizar seu potencial, não apenas de auto-sustentabilidade, mas de ganhos sociais (emprego, renda, inclusão ao consumo de bens culturais). O Ministério da Cultura, como eu disse, tem insistido na abordagem das conexões entre cultura e desenvolvimento e na necessidade de ampliar seu papel, somando às politicas tipicamente compensatórias aquelas capazes de 
diagnosticar e estimular o mercado, ou seja, as empresas e os empreendedores brasileiros que atuam no setor cultural. Trata-se de uma abordagem mais abrangente e integrada.

Tais políticas foram inauguradas nos anos 1990, com a criação dos incentivos da Lei Federal 8.313/1991 (Lei Rouanet) ${ }^{9}$ que institui o Programa Nacional de Apoio à Cultura (Pronac), com mecanismos como o Fundo Nacional de Cultura, o Mecenato e o Fundo de Investimento Cultural e Artístico ${ }^{10}$ : Em 2001 os investimentos em cultura favorecidos pela Lei Rouanet e pela Lei do Audiovisual, por exemplo, chegaram a quase $\mathrm{R} \$ 558$ milhões ${ }^{11}$. A lógica dessa legislação pode permitir a uma empresa abater mais do imposto devido do que seu próprio investimento em cultura ${ }^{12}$. Segundo dados extraídos do portal Marketing \& Cultura as vantagens seriam as seguintes ${ }^{13}$ :

- O projeto cultural pode ser parte da estratégia de marketing da empresa ou de seu produto, com retorno muitas vezes superior às expectativas iniciais;

\footnotetext{
${ }^{8}$ Palestra do Ministro Gilberto Gil no Instituto Rio Branco (Brasília, 2005). Disponível em: http://www.cultura.gov.br/foruns_de_cultura/economia_da_cultura/index.html, consultada em janeiro de 2006.

${ }^{9}$ Ver íntegra da Lei Rouanet em https://www.planalto.gov.br.

${ }^{10}$ Fundo Nacional da Cultura - O Fundo Nacional de Cultura recebe recursos de diversas instituições, públicas e privadas, repassando-os a projetos de natureza comunitária ou de caráter experimental que, sem o financiamento público, dificilmente despertariam o interesse do investidor privado.

Mecenato - O mecenato consiste no apoio de pessoas físicas e jurídicas, que realizam doações ou patrocínios diretamente a projetos culturais aprovados pelo Ministério da Cultura.

Fundo de Investimento Cultural e Artístico (FICART) - O FICART destina-se à captação de recursos no mercado financeiro mediante oferecimento de quotas de fundos em condomínio administrados por instituições financeiras fiscalizadas pela Comissão de Valores Mobiliários (CVM). O valor das quotas do FICART não pode ser deduzido do Imposto de Renda, pois remuneram os investidores com juros e dividendos. Disponível em http://www.marketing-e-cultura.com.br, consultada em 30 de novembro de 2005.

${ }^{11}$ Ver em www.projetobr.com.br, consultada em 30 de novembro de 2005.

12 Ver: "Empresas que investem em cultura lucram mais" em http:// www.portaldovoluntario.org.br, consultada em 30 de novembro de 2005.

${ }^{13}$ http://www.marketing-e-cultura.com.br, consultada em novembro de 2005.
} 
- O custo do marketing através da cultura costuma ser menor se comparado com os custos de outras campanhas promocionais;

- O patrocínio de projetos culturais permite inserção do investidor no meio social, pois quem investe em cultura sempre é visto com simpatia pelo público em geral;

- O investimento cultural bem planejado pode reduzir a carga tributária da empresa, principalmente porque o valor investido, em muitos casos, é dedutível também como despesa operacional;

- Permite ao investidor acompanhar e fiscalizar mais de perto a aplicação adequada de recursos que seriam direcionados aos cofres públicos;

- Em alguns casos, garante até $25 \%$ dos produtos originados pelo projeto cultural para distribuição entre clientes ou fornecedores da empresa, como brinde ou mídia institucional.

A cultura é percebida não só como um bom negócio em si, como também um "elemento estratégico de desenvolvimento econômico"14. Em Recife, no Seminário Internacional em Economia da Cultura promovido pela Fundação Joaquim Nabuco (Fundaj) em parceria com a Unesco, com o Ministério da Cultura, com o Instituto Itaú Cultural, com a Universidade Federal do Rio Grande do Sul e com a Fundação do Patrimônio Artístico e Cultural de Pernambuco, realizado em julho de 2007, diretrizes para o desenvolvimento econômico através da cultura foram traçados, assim como foi "a etapa inicial de uma série de ações da Fundação Joaquim Nabuco neste campo, abrindo caminho para a criação da primeira turma do Curso de Pós Graduação em Economia da Cultura"15.

\footnotetext{
${ }^{14}$ www.cultura.gov.br/noticias/noticias_do_minc, consultada em 16 de agosto de 2007, sobre o Seminário Internacional em Economia da Cultura.

15 www.fundaj.gov.br, consultada em 23 de agosto de 2007.
} 
Para esse evento foram produzidos artigos que revelam o pensamento do empresariado da relação entre desenvolvimento e cultura que fundamentalmente aponta para a cultura como uma promissora alavanca econômica ${ }^{16}$. O que os investidores ressaltam é, principalmente, a capacidade do investimento no setor cultural gerar lucro.

Em artigo produzido pela superintendente do Santander Cultural Liliana Magalhães, por exemplo, são apontadas vantagens do investimento em marketing cultural, que vem a ser, segundo a autora, "uma prática de gestão que inclui e vincula necessariamente os atores públicos, privados e comunitários"17. Segundo Liliana Magalhães, os ganhos no investimento em marketing cultural são os seguintes:

- ganho com visibilidade, na divulgação de seu conhecimento, práticas e serviços;

- reforço do posicionamento institucional e de mercado;

- comercialização de produtos;

- geração de negócios;

- promoção de intercâmbio;

- potencialização de atuação em rede, com universos e práticas diferentes, capazes de gerar produtos com a soma do que cada um tem a oferecer ${ }^{18}$.

\footnotetext{
${ }^{16}$ Entre os "mais influentes e poderosos no investimento de cultura do país" presentes nas discussões promovidas pelo Seminário,, segundo a matéria publicada na Folha de Pernambuco em 16 de julho de 2007, está o superintendente do Itaú Cultural, o diretor do SESC-SP, a gerente de patrocínio da Petrobrás e a superintendente do Santander Cultural (www.fundaj.gov.br, consultada em 23 de agosto de 2007).

17 www.fundaj.gov.br, consultada em 23 de agosto de 2007.

${ }^{18}$ idem.
}

O valor econômico da cultura:... 
O depoimento de Liliana Magalhães ratifica as supostas vantagens e a capacidade de obtenção de lucro ao se desenvolver programas culturais como estratégia de negócios:

Com o papel mobilizador desempenhado pelo Santander Cultural, o empreendimento funcionou como uma antena parabólica, capaz de captar no mercado parceiros e iniciativas que agregaram produtos e serviços ao projeto, e assim praticamente duplicaram o investimento direto da instituição. Enquanto o Santander Cultural investiu cerca de $\mathbf{R} \mathbf{\$} \mathbf{9 0 0}$ mil na mostra, as instituições parceiras aportaram produtos, serviços, recursos humanos, conhecimento e chancela, gerando um valor de cash equivalente estimado em $\mathbf{R} \$ \mathbf{7 5 3}$ mil. Todos os parceiros aproveitaram o espaço para realizar demonstração de seus produtos, mobilizar clientes, efetuar vendas e capacitar o público para os usos inovadores dos produtos ${ }^{19}$.

Através do que foi exposto, percebemos que os investimentos são direcionados, estrategicamente, para certos produtos culturais capazes de contribuir para a concretização dos objetivos das empresas o lucro. Contrariando os preceitos do próprio relatório da Unesco que aponta para investimentos que contribuam para o apoio à diversidade cultural, tal situação revela a contradição em se propor um projeto de desenvolvimento econômico que atenda às questões de desenvolvimento cultural e humana.

\section{Perspectivas para o prosseguimento do estudo}

Como vemos, o marketing cultural se utiliza das premissas do relatório da Unesco, onde a "democratização do acesso à cultura", a "promoção de diversidade cultural" e a "defesa e preservação da identidade de um povo", entre outros jargões, vêm sendo utilizados para justificar os seus fins.

${ }^{19}$ idem. 
Reiteramos aqui o princípio de que há uma contradição entre a intenção de que a cultura seja um "fator de desenvolvimento econômico" - visando contribuir para a valorização do capital - e a intenção de que a cultura, nesse contexto produtivo, possa, de fato, defender a "identidade de um povo", promover a "democratização do acesso à cultura" e a promoção da "diversidade cultural".

Pelo que vimos, no âmbito da economia e da política, o conceito de cultura aparece de forma tanto ampla quanto vaga, tendo como apoio os citados jargões. Entretanto, as estratégias de marketing cultural, assim como a classificação do IBGE citada anteriormente, por exemplo, deixam claro que quando se fala em cultura se fala em serviços ou produtos com alto potencial como valor de troca, seja para a comercialização do produto em si ou como "agregador" de valor.

Percebemos o termo cultura como uma palavra que está longe de ser neutra, e que, por ser de grande elasticidade, permite aos que a utilizam adequá-la ao sentido de sua conveniência. Pode servir aos preceitos religiosos, pode servir aos argumentos ideológicos, pode servir ao mercado, às estratégias de marketing, ao discurso político. Isso porque essa palavra trás de forma implícita valores que traduziriam aspirações dignas da espécie humana, um caráter intrinsecamente "bom" ou "positivo". Assim, "a cultura tudo pode, e tudo pode de bom no e para 'o social'" (TEIXEIRA COELHO, 2008, p. 10).

O slogan da gravadora Som Livre, por exemplo, utilizado na época áurea da comercialização de discos, era enfático: "Disco é Cultura". Teixeira Coelho (2004) diz que "o significado que se pretendia passar era que o consumo de discos conduzia àquele estado de espírito desenvolvido" (idem p.105).

Teixeira Coelho (2008) nos chama atenção para os usos que se fez (e que se faz) da cultura, especialmente sobre o caso do Brasil. A noção de cultura, diz ele,

164 O valor econômico da cultura:... 
depois de ter servido como instrumento de integração nacional sob a ideologia da ditadura militar entre 1964 e 1984, a grande palavra de ordem para a cultura agora, nestes anos de 2003 e 2004, é inclusão social, da qual a cultura surge como um veículo aparentemente e forçadamente privilegiado (uma vez que da economia ou do planejamento econômico neste momento pouco se pode esperar nesse sentido) (TEIXEIRA COELHO, 2008, p. 10).

Dessa forma, procuramos destacar que o que se vê no discurso político, na fala do empresariado e dos que apelam para o marketing cultural como forma de se agregar valor aos seus produtos, é a cultura como um mero "fator de desenvolvimento econômico".

Tendo por objetivo questionar as práticas e as políticas que em seu discurso parecem favorecer a idéia da democratização do acesso à cultura, da promoção da diversidade cultural e do fortalecimento da identidade cultural brasileira, mas que na verdade utilizam a cultura como um meio para atingir outro fim - a valorização do capital - nossa concepção de cultura segue em outro sentido. Não seria de nosso interesse sistematizar ou definir o que é ou não cultura (e muito menos engessar esse conceito), mas sim destacar primeiro, a contradição entre a proposta do entendimento da cultura como "fator de desenvolvimento econômico" ao lado da cultura como desenvolvimento humano, o que procuramos observar nas seções anteriores deste artigo.

Os estudos subseqüentes que pretendemos realizar partem da idéia da cultura como um processo. Nesse sentido a cultura seria um processo contínuo de ação, ação que é movida pela experiência vivida e trocada. Assim, seus resultados são inesperados e o homem é o ser ativo dessa ação. De acordo com os estudos de Williams (1969), a cultura seria o

modo por que reagimos em pensamento e em sentimento à mudança de condições por que passou a nossa vida. Chamamos de cultura a nossa resposta aos acontecimentos (...) que determinaram a mudança das condições humanas. Essas condições foram criadas pelo homem e por ele modificadas (WILLIAMS, 1969, p.305). 
O que se destaca nessa concepção de cultura é entendê-la não como algo que precede o homem, que nasce com ele ou que pode ser prevista, mas sim como o resultado da realização de sua história. Não é determinada nem determinante, pois atua em duplo sentido. Isso porque não seria um campo neutro, mas um campo de disputas, de embates que irão constituir a história.

Tendo como premissa que as propostas das políticas públicas para a cultura são determinadas pelo mercado, e, como Eagleton, que "são os interesses políticos que, geralmente, governam os culturais, e ao fazer isso definem uma versão particular de humanidade" (EAGLETON, 2005, p. 18), nossa perspectiva é a de uma cultura "que é continuamente refeita e redefinida pela prática coletiva de seus membros, e não aquela na qual valores criados pelos poucos são depois assumidos e vividos passivamente por muitos" (idem, p.169).

Em recente debate promovido pelo Observatório Itaú Cultural, transmitido ao vivo pela internet em 12 de novembro de 2007, Teixeira Coelho observa que o antropólogo Lévi-Strauss já alertara a Unesco que um projeto de desenvolvimento cultural não deveria apoiar a preservação de produtos culturais, mas sim a preservação das condições necessárias à produção da diversidade cultural. Mas quais seriam as condições necessárias para um desenvolvimento cultural que, de fato, promova o desenvolvimento humano? Isso, certamente, implicaria em discutir toda a organização econômica-político-social.

Entendemos que falar de cultura é, antes de tudo, falar de vida social e de ação. Isso quer dizer que enquanto as condições de vida social não forem minimamente satisfeitas, uma ação cultural estrita não terá efeito. Ou seja, para que uma ação cultural se efetive é necessário um conjunto de ações que viabilize a vida social do sujeito. Mas para isso é necessário pensar em um outro tipo de sociedade, e é nesse sentido que daremos continuidade a nossa investigação e a nossa argumentação crítica. 


\section{Referências Bibliográficas}

CEVASCO, Maria Elisa. Dez lições sobre estudos culturais. São Paulo: Boitempo, 2003.

CUÉLLAR, Javier Pérez de (org.). Nossa diversidade criadora: relatório da Comissão Mundial de Cultura e Desenvolvimento. Campinas, SP: Papirus, Brasília: UNESCO, 1997.

EAGLETON, Terry. A idéia de cultura. São Paulo: Editora UNESP, 2005.

EARP, Fábio Sá (org.). Pão e circo: fronteiras e perspectivas da economia do entretenimento. Rio de Janeiro: Palavra e Imagem, 2002.

FISCHER, Ernst. A necessidade da arte. São Paulo: Círculo do Livro, s.d.

HOLLANDA, Heloísa Buarque de. Considerações sobre o conceito de cultura. In: Economia da cultura: a força da indústria cultural no Rio de janeiro. Rio de Janeiro: Faperj e Coppe/UFRJ, 2002, pp.25-32.

INSTITUTO BRASILEIRO DE GEOGRAFIA E ESTATÍSTICA (IBGE). Sistema de informações e indicadores culturais 2003. Rio de Janeiro: IBGE, 2006.

REIS, Ana Carla Fonseca. Marketing cultural e financiamento da cultura: teoria e prática em um estudo internacional comparado. São Paulo: Pioneira Thompson Learning, 2003. 
TEIXEIRA COELHO. A cultura e seu contrário: cultura, arte e política pós2001. São Paulo: Iluminuras: Itaú Cultural, 2008.

. Dicionário crítico de política cultural. São Paulo:

Iluminuras, 2004.

TRIGO, Luiz Gonzaga Godoi. Entretenimento: uma crítica aberta. São Paulo: Editora Senac São Paulo, 2003.

WILLIAMS, Raymond. Cultura e Sociedade. São Paulo: Editora Nacional, 1969. 